\title{
SMALLER SIZE LARYNGEAL MASK AIRWAY AND GUM ELASTIC BOUGIE COMBINATION IS A FAILSAFE TECHNIQUE FOR TRACHEAL INTUBATION IN A CHILD WITH TEMPOROMANDIBULAR JOINT ANKYLOSIS
}

Satyendra S. Yadav ${ }^{1}$, Suman Gupta ${ }^{2}$, B. Choudhary ${ }^{3}$

\section{HOW TO CITE THIS ARTICLE:}

Satyendra S. Yadav, Suman Gupta, B. Choudhary. "Smaller Size Laryngeal Mask Airway and Gum Elastic Bougie Combination is a Failsafe Technique for Tracheal Intubation in a Child with Temporomandibular Joint Ankylosis". Journal of Evolution of Medical and Dental Sciences 2014; Vol. 3, Issue 52, October 13;

Page: $12225-12229$, DOI: $10.14260 /$ jemds/2014/3615

ABSTRACT: So many men's, so many opinions are there for managing a difficult airway in a child with temporomandibular joint ankylosis (TMJA). It is an exceptionally challenging even in hands of experienced anesthesiologist. Success lies in doing ordinary things extraordinarily well. At times newer equipments and techniques turn out to be failure with uncooperative child. Here we present a case report of TMJA where successful intubation was possible in child with limited mouth opening with the aid of smaller size Laryngeal mask airway.

KEYWORDS: Laryngeal mask, Temporomandibular ankylosis, pediatric, difficult airway.

INTRODUCTION: Temporomandibular joint (TMJ) is one of the synovial joint between the squamous portion of temporal bone and a condyle of the mandible. TMJ exhibit two functions. First rotation of the condyle and Second forward displacement of the condyle. It's Ankylosis, a Greek word meaning "stiff joint" [1] is an intracapsular union of the disc condyle complex to temporal articular surface that restricts mandibular movement including the fibrous adhesion or bony fusion between condyles, disc, glenoid fossa and articular eminence. ${ }^{[2]}$

TMJA is of two types. True ankylosis: This is usually bilateral and is associated with ankylosis of other joints. False ankylosis: This is unilateral and secondary to burn, trauma, irradiation, and temporal craniotomy. [3] Its occurrence during childhood affect not only facial development i.e. disproportion, distortion, dysmobility but also dentition, speech and overall growth of the child. An Airway is the first and foremost concern of any anesthesiologist. Most important determinant of adequate airway is Temporomandibular Joint mobility. Its ankylosis results in variable restriction of jaw mobility. Most of the cases result from a trauma (31\%-98\%) like a delivery by forceps; rare etiologies are congenital, as a part of malformative syndrome i.e.

Treacher Collins syndrome, Pierre Robin syndrome, Goldenhar syndrome, or as a single feature without malformation, injection and reasons unknown. ${ }^{[4]}$ Patient with TMJA cannot open the mouth widely and have variable degree of facial disfigurement, those results in serious problem for airway management. The problem become intensified and challenging for anesthesiologists if the patient is a un co-operative pediatric age group. Anesthesiologist should previse expected difficulty to avoid undue perianaesthetic panic. Here we present a pediatric case of difficult airway with TMJA, managed with the aid of Laryngeal mask airway.

CASE REPORT: A 19-Kg 9-year-old boy presented with restricted mouth opening since birth, diagnosed as TMJA and was on soft diet only. He was scheduled for unilateral coronoidectomy under general anesthesia. Examination revealed a healthy looking boy with fullness of cheek and mild facial 
asymmetry resulting from hypo plastic growth of one side mandible (Figure.1). No other abnormality was detected. Airway examination revealed Mallampati grade IV. Mouth opening was restricted to less than a finger breath (Figure.2). Laboratory investigations were in normal limits. Computed Tomography Scan showed bilateral TMJA with skeletal hypoplasia of mandible.

Child and parent were counseled regarding the anticipated difficult airway and proceeding to surgical airway tracheostomy if required. Difficult airway management equipment and all resuscitation drugs were prepared. Ear Nose Throat (ENT) surgeon was made available if surgical airway required.

Preferred approach was Blind nasal intubation (BNI) under spontaneous ventilation .No premedication was administered. In the premedication room, First of all bilateral nasal patency was checked, vasoconstriction of nasal mucosa was achieved by instilling two drops of xylometazoline in each nostril. Topical anesthesia of upper airway is by nebulization with lignocaine $4 \%(2.5 \mathrm{ml})$ for 15 minutes. A 20G IV cannula placed on left hand and Ringer lactate (RL) started as a maintenance fluid.

In the operation room Standard monitoring Electrocardiogram (ECG), Noninvasive blood pressure(NIBP), pulse oximeter ( $\left.\mathrm{sp}_{2}\right)$, were attached .After pre oxygenation, the child was made asleep via gas induction with halothane and $100 \% 0_{2}$, and was breathing spontaneously. Right nostril was lubricated with lignocaine jelly ,A $5 \mathrm{~mm}$ internal diameter cuffed endotracheal tube was put through it while continuously monitoring the breath sounds as the tube advances, but failed to negotiate trachea ,Endotracheal tube was withdrawn and spontaneous ventilation reinstituted.

As BNI was a failure. Alternative approach applied a small for his age size Laryngeal mask airway (LMA) NO. 1.5, completely deflated was passed in the oral cavity with corkscrewing movement as mouth opening was restricted, and overinflated with $10 \mathrm{ml}$ of air to accommodate pharyngeal space. It was connected to pediatric Ayer's T Piece circuit, reservoir bag was moving as child was breathing spontaneously, through it a pediatric gum elastic bougie was passed on which 4.5 uncuffed ETT is railroaded. Finally bougie was withdrawn and ETT and LMA both were secured as shown in (Fig3.) and surgery was preceded with both in situ. We were reluctant to remove LMA in fear of losing airway.

Neuromuscular blocking agent (NMB) was given after confirming position of endotracheal tube. General anesthesia was maintained on $0_{2}+\mathrm{N}_{2} 0+$ Halothane with injection atracurium as neuromuscular blocking agent. Duration of surgery was 3hours. No significant blood loss was there. Mouth opening of approximately three fingers achieved (Figure. 4) just post operatively which may further increase with physiotherapy. NM B reversed; child was allowed to regain consciousness and extubated.

DISCUSSION: Securing an airway in a child with TMJA is thought-provoking and challenging for anesthesiologist. Identification of characteristics of difficult airway and formulating a plan for managing problem are essential principles of anesthesia practice.[5] Conventional laryngoscopy tracheal intubation cannot be performed if the maximal mouth opening is less than $2.5 \mathrm{~mm}$ as any part of the larynx will not be visualized.[6]

Alternative to laryngoscopy include nasal fibrotic intubation, BNI, Retrograde tracheal intubation. At times all these technique becomes all the more troublesome and impossible because of lack of cooperation in pediatric age group, even in the expert hands there is a high possibility of failure, trauma and bleeding.[4] 
Recently, LMA has revolutionized the airway management. The LMA can be inserted completely deflated if the space is limited. Head and neck vascular malformations, [7] PierreRobins, ${ }^{[7,8]}$ Treacher Collins syndrome, ${ }^{[7,9,10]}$ Goldenhar syndrome ${ }^{[7]}$ and mucopolysaccharoides ${ }^{[11]}$ are examples of condition that have been successfully managed with LMA. This approach avoid excessive instrumentation, minimizes the risk of trauma and further airway obstruction by bleeding or edema and circumvent the can't intubate can't ventilate scenario.[7]

LMA has also been used as a condoit for bougie or fibreoptic intubation. [10] Considering all this our technique is failsafe where we were able to pass a small sized, completely deflated LMA through limited mouth opening, using it as a conduit pediatric gum elastic bougie, and over that uncuffed ETT 4.5 was Passed in case of TMJA. The another biggest challenge after intubating through LMA is how to remove the LMA without dislodging the ETT from trachea. This difficulty is unique to the pediatric anesthesiologist, because the length of an age appropriate pediatric ETT and LMA are similar, the proximal end of ETT tends to disappear into the LMA once the ETT has passed through the vocal cord. [10]

Various methods have been used to extend the length of ETT, by wedging another ETT into the distal end of intubated ETT using a cut endotracheal connector as a female to female adapter ${ }^{[10]}$ using long foreign body removing forceps holding the ETT while the LMA is removed[12] In our case distal end of ETT did not buried into the LMA as we used small for age sized LMA, in fact ETT and is connecter were projecting outside the LMA as seen in (Figure.4) through which we were able to connect Ayer's T piece pediatric circuit. We secured both ETT and LMA fearing dislodging of ETT.

CONCLUSION: To summarize, it is important to recognize that none of the technique is safest and standard in managing a pediatric difficult airway in TMJA. Considering patient characteristics, anesthesiologist skill, team co-operation can change any failsafe approach to failure and therefore back up plans and equipment are essential.

\section{REFERENCES:}

1. Malik NA .Text book of oral and maxillofacial surgery, $1^{\text {st }}$ Ed. New Delhi: Jaypee Brothers Medical Publishers AND (P) AND Ltd; 2002. P. 207-18.

2. Long X, Li X, Cheng Y, Yan X, Qin L, Qiao Y, Deng M. Preservation of disc for treatment of traumatic temporomandibular joint ankylosis. J Oral Maxillofac surg. 2005; 63 (7): 897-902.

3. Marhatta MN, Acharya SP. Blind nasal intubation in a child with ankylosis of Temporo Mandibular Joint. Nepal Med Coll J 2008; 10 (4): 271-274.

4. Pacheco V, Miguel M, Figueiredo Lima J. Congenital bilateral ankylosis, a case report of totally impaired mouth opening. European conference on paediatrician aesthesia P.107.

5. Practice guidelines for management of the difficult airway. An updated report by the American society of Anaesthesiologist Task force on management of difficult airway. Anaesthesiology 2003; 98 (5): 1269-77.

6. Aiello G, Metcalf I. Anaesthetic implications of Temporomandibular joint disease. Can J Anaesth1992; 39 (6): 610-16.

7. Ramesh S, Jayanthi R. Supraglottic airway devices in children. Indian J Anaesth 2011; 55 (5): 476-482. 


\section{CASE REPORT}

8. Beveridge ME. Laryngeal mask anaesthesia for repair of cleft palate. Anaesthesia 1989; 44 (8): 656-7.

9. Ebata T, Nishiki S, Masuda A, Amaha K. Anaesthesia for Treacher Collins syndrome using Laryngeal mask airway. Can J Anaesth 1991; 38 (8): 1043-1045.

10. Muraika L, Heyman JS, Shevchenko Y. Fibreoptic tracheal intubation through a Laryngeal Mask Airway in a child with Treacher Collins Syndrome.AnesthAnalg2003; 97 (5): 1298-9.

11. Walker RW, Allen DL, Rothera MR. A fibreoptic intubation technique for children with mucopolysaccharidoses using the Laryngeal mask airway. Paediatr Anaesth 1997; 7 (5): 421-6.

12. Bahk JH, Kim CS .A method for removing the laryngeal mask airway after using it as an intubation guide Anesthesiology1997; 86 (5): 1218.

Figure 1: Patient with Temporomandibular joint ankylosis with mild facial asymmetry on one side of mandible.

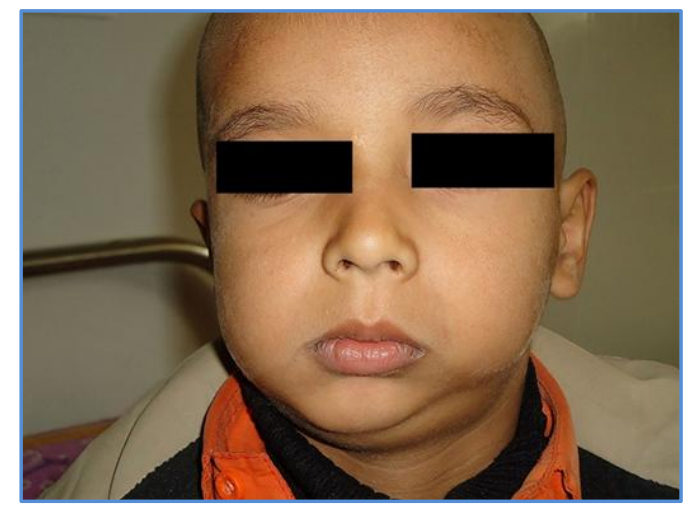

Figure 1

Figure 2: Showing restricted mouth opening.

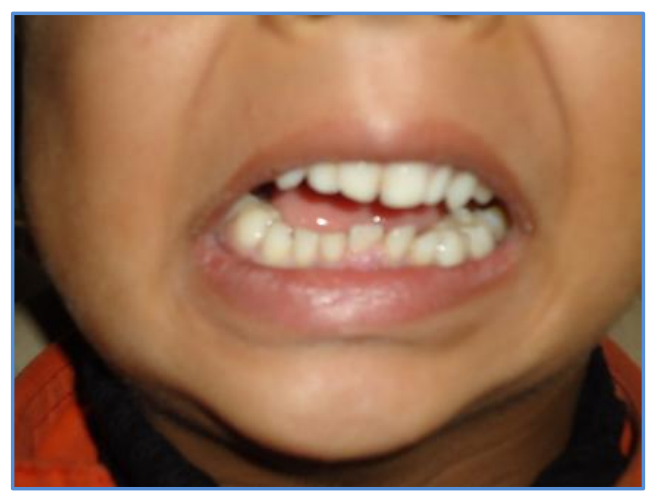

Figure 2 


\section{CASE REPORT}

Figure 3: Child with secured distal end of Laryngeal Mask Airway (broad arrow) with institute endotracheal tube connected (narrow arrow) to breathing circuit.

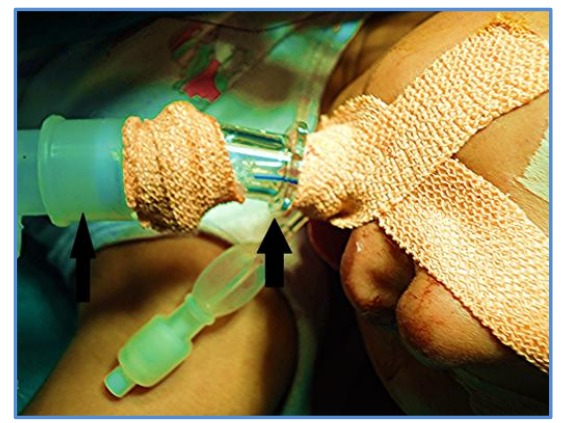

Figure 3

Figure 4: Showing postoperative increased mouth opening.

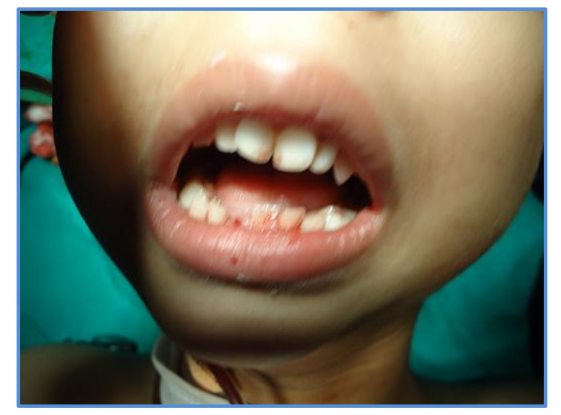

\section{Figure 4}

\section{AUTHORS:}

1. Satyendra S. Yadav

2. Suman Gupta

3. B. Choudhary

\section{PARTICULARS OF CONTRIBUTORS:}

1. Assistant Professor, Department of Anaesthesiology, J.A. Group of Hospitals, G.R. Medical College, Gwalior (M.P), India.

2. Assistant Professor, Department of Anaesthesiology, J.A. Group of Hospitals, G.R. Medical College, Gwalior (M.P), India.

3. Professor \& HOD, Department of Anaesthesiology, J.A. Group of Hospitals, G.R. Medical College, Gwalior (M.P), India.
NAME ADDRESS EMAIL ID OF THE CORRESPONDING AUTHOR:

Dr. Satyendra S. Yadav, Department of Anaesthesiology, J.A. Group of Hospitals, G.R. Medical College, Gwalior, Madhya Pradesh, India.

Email: drssy_17@yahoomail.com

Date of Submission: 24/09/2014. Date of Peer Review: 25/09/2014. Date of Acceptance: 04/10/2014. Date of Publishing: 13/10/2014. 